\title{
Melamine and its Effect on Coagulation System
}

\author{
Viroj Wiwanitkit
}

Received: 26 March 2009/Accepted: 26 April 2010/Published online: 28 September 2010

(c) Indian Society of Haematology \& Transfusion Medicine 2010

A recent emerging health problem is the tainted milk from China. The contamination of melamine in milk was reported to relate to death of several infants exposed to the problematic product [1]. The renal pathology is the main manifestation in intoxicated case. Here, the author focuses the interest on the effect of melamine on coagulation system. First, biochemically, it is well accepted that melamine can affect the coagulation system. Although there is no direct evidence that melamine can deteriorate the vascular structure or coagulation factor, suppressive to the blood platelet aggregation can be seen [2]. Second, the melamine can be directly absorbed into blood stream before passed to the nephron for excreted out. There is a chance for interaction between melamine and platelet in the blood stream. This might lead to the conclusion that melamine might cause the bleeding problem due to disturbance on coagulation system. However, this must be the dose related phenomenon. Only cases with large dose exposure can present the symptoms. This hypothesis might be a good explanation for observation on hematuria in exposed case that has no renal glomerular pathology or urolithiasis [3].

\section{References}

1. Melamine (1999) IARC Monogr Eval Carcinog Risks Hum 73:329-338

2. Reininger AJ, Heijnen HF, Schumann H, Specht HM, Schramm W, Ruggeri ZM (2006) Mechanism of platelet adhesion to von Willebrand factor and microparticle formation under high shear stress. Blood 107(9):3537-3545

3. Lam HS, Ng PC, Chu WC, Wong W, Chan DF, Ho SS, Wong KT, Ahuja AT, Li CK (2008) Renal screening in children after exposure to low dose melamine in Hong Kong: cross sectional study. BMJ 37:a2991

V. Wiwanitkit $(\bowtie)$

Wiwanitkit House, Bangkhae, Bangkok 10160, Thailand

e-mail:wviroj@yahoo.com 